\title{
Marketing Strategy Analysis of RT-Mart Supermarket Under the Background of Epidemic Situation
}

\author{
Junyan Du \\ School of Management, Shandong University of Technology, Zibo 255000, China
}

\begin{abstract}
This paper takes the RT-Mart supermarket under the background of epidemic as the research object, analyzes the current situation of online and offline operation, and finds out the existing problems. Through SWOT analysis and Porter five force model analysis, the paper discusses the challenges that the supermarket of RT-mart is facing at present. And through two questionnaires, we can find the weak points of marketing in RT-Mart more accurately. According to this, we put forward constructive suggestions and some safeguard measures.
\end{abstract}

Keywords: Chain supermarket, Marketing strategy, COVID-19, SWOT, Porter's Five Forces.

\section{Introduction}

For large chain enterprises, chain operation mode is the foundation of their survival and development. In the middle of the 19th century, chain operation, as a new business organization model, developed rapidly with the essence of its low risk capital expansion to form economies of scale. In the 1980s, chain operation started in China. Up to now, there are hundreds of chain enterprises in China, and the average subsidiary company is also hundreds. Chain business model plays an increasingly important role in the development and transformation of enterprises, and it is also the foundation for the survival and development of chain enterprises.

The retail industry is closely related to people's life. The sudden outbreak of the new coronavirus in 2020 will undoubtedly be a big test for the entity enterprises, especially the chain business enterprises. Combined with the entry of large foreign chain enterprises, China's retail industry is facing a "great change unseen in a century". In the first half of 2020 , the total retail sales of consumer goods fell by 11.4 percent compared with the same period last year, according to the Risk Management Report of China's Retail Industry 2020 released by the China Chain Store Association. At the same time, the development of network technology brings with it the change of consumption pattern and the uncertainty of the market environment, which brings the corresponding opportunities to the chain enterprises. As a chain enterprise with more than 20 years of development history, RT-Mart has numerous subsidiaries. However, through field investigation and literature research, it is found that there are some problems in its marketing strategy. In general, these problems are common in all walks of life under the background of the current normal epidemic. So, who can give priority to grasp the market development trend and constantly optimize marketing strategy, who can be in an invincible position, get considerable development.

\section{Marketing Status of RT-Mart Supermarket}

\subsection{Introduction of RT-Mart Supermarket}

RT-Mart supermarket is set up by Taiwan's Runtai group. At first, Runtai group's main business focused on the textile industry. However, in the same period, the chain operation mode of the United States is developing in full swing, spreading to the world and impacting the operation of all walks of life in all countries. Therefore, the group had to start to seek transformation, RT-Mart was able to set up. RT-Mart entered the mainland market in 1997 and set up the first RT-Mart supermarket in Shanghai. As of December 2019, RT-Mart has 414 stores across the country, involving 232 cities. The opening of chain stores promotes the acquisition of higher scale benefits.

\subsection{Operation Status of RT-Mart Supermarket}

RT-mart, by virtue of its chain operation mode, has been constantly expanding and expanding its market share, which has been recognized and recognized by many consumers. RT-Mart supermarket "fresh, cheap, comfortable, convenient" business philosophy is its continuous accumulation of customers, and form the source of customer loyalty. It is true, but more and more supermarkets see the benefits brought by the chain operation mode, and have changed the operation mode to enter the market competition. At the same time, RT-Mart supermarket in the homogeneous, fierce competition realized that it can not follow the rules, according to the original mode of marketing development, otherwise it will be eliminated by the times. Therefore, RT-Mart supermarket broke the Convention, changed its marketing ideas, opened up online sales channels, and paid attention to the organic integration of online and offline sales.

\subsubsection{Online Business}

RT-Mart supermarket develops online traffic based on the accumulated customers of its physical stores. In June 2013, RT-Mart supermarket invested in the creation of the $\mathrm{O} 2 \mathrm{O}$ platform "Feiniu net", with the main business of fresh $\mathrm{O} 2 \mathrm{O}$, store delivery $\mathrm{O} 2 \mathrm{O}$, store electronic screen $\mathrm{O} 2 \mathrm{O}$ and Qianxiang Wanguan O2O. These business models have promoted RT-mart to continuously improve its logistics 
distribution and strengthen food safety supervision, greatly enriched RT-mart's marketing, and also increased consumers' favor for RT-Mart. At the same time, the corresponding app "Feiniu Youxian" has been developed. Customers can log in to the "Feiniu Youxian" account or download the "Feiniu Youxian" app separately through "feiniu.com".

However, due to the low customer recognition of "Feiniu Youxian", it is difficult for customers to establish a trust relationship with app. In 2017, "Feiniu Youxian" was officially renamed "RT-Mart Youxian". By virtue of RT-Mart's good brand image and strong influence, consumers are easier to recognize and increase their sense of identity, which is conducive to the promotion of app, thus promoting the development of online sales. "RT-Mart excellent fresh" is a young, fashionable, convenient and exquisite Internet fresh supermarket. Online ordering and offline distribution are more in line with the fast pace of modern social and economic development, catering to the new consumption needs of consumers, and better implementing the business philosophy of RT-Mart supermarket.

With the development of the Internet, the business model of enterprises is bound to be affected. The future business situation is undoubtedly the organic integration of online and offline, mutual promotion and common development. Based on this prospect, in 2017, Alibaba took a stake in RT-mart to carry out cross-border cooperation. The cooperation between Alibaba and RT-Mart has not only opened up Alibaba's offline retail market, but also brought traffic to RT-Mart's online sales. In 2019, "Taoxianda" app will be officially launched, with free shipping when the price is over 39 yuan. You can choose the delivery time at will, and promise one-hour delivery within three kilometers. At the time of the epidemic in 2020, "Taoxianda" is the main online sales channel of RT-Mart supermarket. At present, "Taoxianda" also launched the "delayed closing" service, which fully considered and met the needs of consumers, and also promoted the growth of sales performance.

\subsubsection{Operation Status of Offline Stores}

After Alibaba took a stake in RT-Mart, it gradually transformed its stores. In 2018, half of RT-art's stores have accepted digital transformation. WeChat, Alipay and other electronic payment applications are widely used, and the self-service checkout system is also improving. These changes have greatly improved the shopping experience of consumers, making consumption easier, faster and more liberalized. At the same time, the use of self-service checkout system also reduces the user cost for enterprises, and makes the realization of integral system and membership system more convenient.

During the epidemic period, the number of online orders increased sharply, and the existing online sales system of RT-Mart supermarket has been unable to meet the growing demand for orders. Therefore, RT-Mart supermarket borrowed the hang chain intelligent logistics technology of HEMA Xiansheng, greatly improved the logistics distribution efficiency of RT-Mart supermarket during the epidemic period, and also improved the logistics distribution system of RT-Mart.

With the upgrading of the consumption structure, the whole operation system of RT-Mart is also upgrading and developing. It has successfully built a national brand and attracted consumers of all ages to come to shop, so that RT-mart will always maintain the characteristics of the times and accumulate strength for its sustainable development.

\section{Challenges Faced by RT-Mart Supermarket Marketing}

\subsection{SWOT Analysis}

\subsubsection{Advantage analysis}

1)Strong brand influence

As a chain enterprise with more than 20 years of history, RT-Mart's image of being close to the people has been deeply rooted in the hearts of the people. Therefore, consumers are loyal to them. In this paper, the local RT-Mart supermarket, consumers generally tend to buy here. Nationwide, many consumers have joined RT-Mart's members. Compared with Wal Mart, RT-Mart has a better reputation. Consumers believe that they can "buy at ease and eat at ease" here.

\section{2)Uperior geographical location}

The RT-Mart supermarket studied in this paper is located on one side of the $\mathrm{T}$-junction, and on the other side is the pedestrian street, which ensures the passenger flow. There are all kinds of milk tea shops and desserts around. It is only three kilometers away from the nearby university, which is the most convenient place for students to purchase at weekends. Moreover, the parking space at the gate of the supermarket is open, which is also an important factor to attract consumers to choose supermarkets.

\section{3)The promotion advertisement is timely and diversified}

RT-Mart supermarket closely follows the market vane, whether it is a holiday or "creation Festival", will carry out the corresponding promotion. For example, during the Chinese new year, the store is decorated as "China Red", full of blessings, "Happy New Year", "congratulations on the new year" and other words can be seen everywhere. In addition, the background music plays, which sets off the festival atmosphere and creates a sense of belonging. Visual and auditory stimulation will stimulate consumers' desire to buy and make unplanned purchases.

4)The goods are cheap and good in quality

The essence of the chain operation mode adopted by RT- Mart supermarket is to reduce the cost by continuously expanding the scale, so as to achieve scale efficiency. Therefore, in order to seize the market share and expand the business scale, 
RT-mart's daily necessities, such as rice, noodles and oil, are mostly cheap. RT-mart to attract consumers, small profits and quick turnover, the shortest time to expand, profit growth.

\subsubsection{Weakness analysis}

1)Lack of professionals, backward management mode

Most of the management in the store are promoted by experienced employees, but the overall quality of the employees is not high, the cultural level is general, and they lack the necessary modern management knowledge and skills. Therefore, some of the existing management are not high quality. During the epidemic period, the development of enterprises needs overall planning and specific action policies. However, if there are unnecessary mistakes in supermarket management and formulation of relevant strategies at this time, the impact on supermarkets will be devastating.

\section{2)Lack of standardization, obvious regional differences}

Up to now, RT-Mart has more than 400 stores, but the pricing of products in each region is not uniform, and even the quality is different. After consumers perceive the differences, they will have resistance psychology, which will affect the long-term development of supermarkets.

3)Untimely use and maintenance of new technology equipment

The application of self-checkout system is to provide better convenience for customers and make shopping more free and private. However, through field research, it is found that the self-service checkout system of RT-Mart supermarket is often out of power off state, and some of them are even damaged, but there is no maintenance. During the epidemic period, offline shopping activities basically adhere to the "no touch" principle, so most consumers choose to self-check out instead of going to the manual counter. However, due to the emergence of self-checkout system, it will greatly reduce the sense of shopping experience of consumers and affect the reputation of the whole supermarket.

\subsubsection{Opportunity analysis}

1)The economic situation is getting better and better

In 2020, when the epidemic broke out, the state called on the masses not to go out and consciously isolate themselves at home. However, the development of social economy needs to be promoted by people. The result of not being able to go out is that the enterprise has no manpower and is forced to close down or even go out of business permanently. For supermarkets, it needs one consumer after another to develop. With the normalization of the epidemic situation, the economy is gradually warming up, and all walks of life are rejuvenated and upgraded, and the market demand needs to be met.
2)After the epidemic, consumers' desire for online shopping decreased and tended to offline shopping

During the epidemic, most of the people were isolated at home, and some even did not go out for months. But the necessities of life are essential, and the demand for these products is basically met through online procurement. But after all, it's "cloud shopping". There is still a certain gap between the experience of offline shopping and that of offline shopping. In addition, if you don't go out for several months, you want to go offline shopping.

\section{3)National policy support}

In order to help enterprises rejuvenate under the normalization of the epidemic situation, the state has issued a series of preferential policies. For example, for supermarkets, supermarket staff can enjoy three-month subsidies, which reduces the burden of enterprises. In addition, the central bank has appropriately lowered the loan interest rate to support the economic restart of enterprises.

\section{4)Development of social E-commerce}

During the epidemic period, "live delivery" was once sought after. Even Dong Mingzhu has become the "Queen of goods" with 17.8 billion achievements. Her success in live broadcasting has promoted the integration of Gree online and offline. This indirectly reflects that consumer preferences are changing, which is a new economic growth point. Behind the live selling needs a strong supply chain system to support, which just promotes the development of supply and demand relationship in RT-Mart supermarket.

\subsubsection{Threat analysis}

\section{1)The competition of homogenization is fierce}

In order to restore the economy and help enterprises, the government has introduced policies such as "reducing financing costs" and "lowering loan interest rates". Due to the monopoly competition in the supermarket industry, the low threshold to enter the market, many competitors in the market, and the inseparable relationship between the retail industry and people's lives, some enterprises that were hit hard during the epidemic turned to invest in the supermarket industry. Moreover, the most important feature of monopoly competition is the sale of "similar products with differences". In the case of similar products, the one who can use "differences" to meet the diversified needs of consumers will have the upper hand in competition. Although RT-Mart is a large chain supermarket, it still has different services from small supermarkets in the community. How to "return" this part of customers should also be taken into consideration by RT-Mart.

2)The impact of e-commerce on retail industry 
During the epidemic period, for security reasons, many people didn't go out for several months. Daily necessities and other shopping needs were online shopping. As a result, some people gradually became dependent on online shopping. This way of "moving fingers" and "staying at home" can receive products meets some consumers' needs of "no touch" and "no social". Moreover, compared with offline stores, online stores do not need rent, so commodity prices are lower than physical stores. Online stores are more inclusive and have more kinds of goods than physical stores. It can be seen that with the development of the Internet, the overall consumption situation and consumer demand are upgrading.

3)Consumption power is insufficient and consumption psychology changes

In 2020, when the epidemic broke out, the state urgently called on the masses to isolate themselves at home, enterprises stopped production, and even some employees lost their jobs, which caught some people off guard without savings and financial habits. Without production, there is no source of income. Even if they return to work and production after the epidemic, this group of people also want to make up for the previous "economic blank period". After the epidemic, more people have made savings. We should be more cautious in consumption, adhere to the principle of "rational consumption" and "necessary consumption", and "live within our means" and "enjoy consumption" on an appropriate basis.

\subsection{Analysis of Porter's Five Forces Model}

\subsubsection{Analysis of bargaining power of suppliers}

The bargaining power of suppliers refers to a series of behaviors, such as increasing the supply price, reducing the cost of goods and so on. Of course, whether the supplier has bargaining power is also related to its position in the industry and the number of business orders. For example, when it comes to instant noodles, we think of Master Kang, white elephant and jinmailang. The suppliers of these products have a strong bargaining power, because they have a high degree of national recognition and a small number of suppliers. For suppliers like fruits and vegetables, their bargaining power is naturally weak.

\subsubsection{Analysis of buyer's bargaining power}

For large chain stores like RT-mart, customer loyalty is low. Because there are many similar products available in the market, consumers can choose supermarkets according to their actual needs and preferences. In addition, consumers want to buy products with good quality and low price. They also spend their time "shopping around" and finally buy satisfactory products. The significance of supermarket is to serve consumers, and all things should be centered on consumers. Therefore, from this point of view, consumers also have strong bargaining power.

3.2.3 Analysis of the competitiveness of competitors in the industry
Supermarket industry belongs to monopolistic competition, it is easy to enter the market, so there are many competitors in the market. Because of this, the competition between each other is more intense, and the interests are more closely linked, showing a trend of ebb and flow. According to statistics, the number of domestic existing supermarket stores has exceeded 130000, and the scale of chain supermarkets is also expanding, which undoubtedly intensifies the competition in the industry. However, it is precisely because of the nature that chain operation needs to obtain economic benefits through scale that the industry has a high exit barrier. In addition, during the epidemic period, domestic and foreign enterprises were affected to a certain extent. Foreign chain enterprises have the tendency to enter the Chinese market, which also has a certain impact on the current market competition.

\subsubsection{Analysis of the entry ability of potential competitors}

On the whole, for the chain supermarket industry, a new entrant has low barriers to enter the market. In the short term, in order to avoid risks and reduce costs, we can also make relevant decisions by imitating the "leader" of the industry, so as to catch up with the average level of the industry as soon as possible. In the short run, this plan can be implemented, but in the long run, we should continue to expand and innovate strategies to form our own brand and make use of scale advantages to gain a foothold in the industry.

\subsubsection{Analysis of substitution ability of substitutes}

Substitution in economics refers to the relationship between two products. If there is a substitution relationship between two commodities, then any one of them can meet the needs of consumers. In marketing, substitutes usually attract customers with lower prices, better services or more novel forms, which leads to the market depression of the substitutes and makes profits for their own enterprises. HEMA Xiansheng, a new $\mathrm{O} 2 \mathrm{O}$ retail enterprise, is the main substitute for chain supermarkets. The most different point between HEMA fresh food supermarket and other traditional fresh food supermarkets is that even if you pay online, you have to operate through app. This is a crucial link to realize the organic integration of offline and online. During the epidemic period, even if the number of orders increases sharply, the fresh box horse can ensure the freshness of the food materials and the efficiency of distribution, so as to maximize the consideration of consumers.

\section{Suggestions on Marketing Strategy Optimization of RT-Mart Supermarket}

\subsection{Improve Logistics Distribution System and Improve Distribution Efficiency}

"Taoxianda" is the main channel of online sales of RT-Mart supermarket during the epidemic period. But its distribution scope is limited to three kilometers, and the delivery time is one hour, even sometimes more than one hour. Compared with distribution, the competitive advantage of Taoxianda is less obvious within 30 minutes. In view of this, we should first 
break the limit of three kilometers and expand on a larger scale, so that most regions can enjoy the service of RT-Mart. Secondly, learn the suspension chain logistics system of "box horse fresh life", and gradually explore the logistics system suitable for their own development.

In view of the current epidemic situation, for the sake of epidemic prevention safety, consumers tend to order goods online and choose the right time for delivery. However, when the final goods are delivered to the destination, consumers still need to negotiate with the distributors. Considering that consumers may have the need of "contactless consumption", RT-Mart can set up a "RT-Mart pick-up cabinet" similar to Fengchao express cabinet to meet the needs of consumers. Choose different distribution methods according to the different products, such as fresh products are not easy to keep long, and communicate with consumers what distribution methods to adopt.

\subsection{Traffic Socialization}

The traditional chain enterprises only have offline and entity traffic, and the traditional e-commerce mode is only based on platform traffic. Until the emergence of the new retail model, it has proved that the single traditional chain operation and traditional e-commerce operation will be eliminated sooner or later. According to the report issued by the China Chain Store Association, more than 300 million users will make purchases in WeChat apps in 2020. Private operation shortens the distance between consumers and businesses, so that enterprises can better perceive the real ideas of users. According to the needs, the establishment of the corresponding enterprise WeChat group, enterprise WeChat account, in the group, the circle of friends every day to release discount promotion goods, these measures can make RT-Mart supermarket better close to consumers, become "grounded", which is conducive to shaping the corporate image, enhance customer loyalty. In addition, customers in the same area can rush to buy in the small program, which can also save the cost of distribution and improve the efficiency of distribution.

\subsection{Promote the Deep Integration of Online Sales and Offline Sales}

At present, the new retail model of RT-Mart supermarket is still in the initial stage of development. Taoxianda uses part of the flow of Taobao platform to introduce offline stores, and carries out accurate analysis and marketing on this part of the flow, so as to transform it into physical customers. Under the new retail mode, we should focus on online, and offline stores provide flow for online operation. RT-Mart supermarket can actively publicize and encourage consumers to use its online app to purchase offline, and formulate corresponding discount measures for purchasing with app. At the same time, it should update its online app in time, enrich the form of commodity display, and use video form to make it more intuitive and vivid, so as to improve the online shopping experience. In addition, it can also carry out cross-border marketing with other e-businesses, launch peripheral products, attract young traffic, and help to shape the "young" brand image of RT-Mart.

\subsection{Renew Marketing Idea and Enrich Marketing Means}

With the development and popularization of the Internet, people's ways of receiving information have become more diversified, and this change has also given birth to the personalized needs of consumers. In the past, supermarkets used LED screens, promotional cars and street hair advertisements to promote sales and let consumers know the relevant information. Now, "live broadcasting with goods" is booming. In 2020, the total sales volume of live broadcast of online celebrities Li Jiaqi and Weiya will reach 7 billion, which also reflects the change of consumers' consumption concept. They are more inclined to interact with the anchor in this way of consumption, which is more intuitive and more realistic than the traditional e-commerce platform purchase mode. Therefore, the big RH Mart should seize this opportunity to make good use of the "two micro and one shake" platform (Micro-blog, WeChat, Tiktok) to diversify marketing.

\section{Safeguard Measures of Marketing Strategy Optimization}

The implementation of marketing optimization strategy also needs good system, excellent talent management and advanced technical support.

\subsection{Strengthen the Professional Training of Employees and Introduce Professional Talents}

According to the previous analysis, the overall quality of RT-mart's employees is not high, and the management lacks the corresponding marketing knowledge, so its marketing effect is not significant, and even some unnecessary mistakes will hinder the development of the enterprise. In the 21st century, knowledge is particularly important. If an enterprise wants to develop, it must create new and professional talents. Especially after the epidemic, the enterprise recovery stage, high-tech people can provide constructive advice for the transformation of the enterprise, and design targeted solutions for the weak links of marketing. Therefore, RT-Mart supermarket should first carry out professional training for internal staff to enhance marketing awareness. Secondly, the introduction of professional talents to enhance the overall marketing ability of the management team.

\subsection{Strengthen Health Supervision and Pay Attention to Food Safety}

During the epidemic period, all kinds of external things should be disinfected. Under the background of normalization of epidemic situation, food hygiene and safety have become the first demand of consumers. On the one hand, when consumers do offline shopping, the shopping environment will greatly affect their purchase intention. On the other hand, consumers are more concerned about food safety when they 
choose to buy online, because they can't see the real situation of the goods, which may reduce the online purchase rate of consumers. Therefore, RT-Mart supermarket should consciously carry out the killing work in the store, and formulate the corresponding supervision system to ensure that the goods arrive from the source, the shelves have clear records, and the power and responsibility go to the people. In addition, when carrying out offline distribution, food safety inspection should be carried out. In the distribution of cold and fresh food, there should be a special distribution box to ensure food safety and protect the health of users.

\subsection{Strengthen Technical Support}

"Technology changes life". Whether in daily life or in the workplace, we are bound to find the shadow of high-tech. The new retail model is based on Internet technology. If RT-Mart wants to stand out in the competition of many online supermarkets, it must invest in technology. For example, big data can be used to more accurately push consumers' products with consumption preferences on the "Taoxianda" app, and timely repair app related vulnerabilities to give consumers a better shopping experience. Offline, improve the self-checkout system, realize the liberalization and convenience of checkout method. Robot shopping guides can also be added in the store to attract consumers.

With the continuous development of the Internet, new business models will continue to emerge. The organic integration of online and offline is bound to be the recent development trend. In particular, under the background of the normalization of the epidemic situation, the development of enterprises will face fiercer competition and more complex domestic and international environment. At this time, enterprises should keep pace with the times and innovate constantly, and the future market will be more "humanized" and "personalized".

\section{References}

[1] Liu Yanan. Research on RT mart's marketing strategy based on hierarchy of needs theory[J], Commercial Economy, 2020, (03): 25-29.

[2] Bao Gang. Marketing research of RT Mart chain supermarket[J]. Modern Marketing (Business Edition) 2020, (03): 38-41.

[3] Li Yang, Li Mingxia. Research on the effect of supermarket commodity placement-Taking RT Mart supermarket in Nanchong as an example[J], Modern Marketing (Business Edition), 2020, (03): 46-51.

[4] Grace Aloina, Anggianika Mardhatillah, Anita Christine Sembiring, Uni Pratama Pebrina br Tarigan, Irwan Budiman, Irmalasari Silalahi. Designing market strategy for Indonesian dining house in Industrial 4.0 era[J]. IOP Conference Series: Materials Science and Engineering, 2019, 505(1): 49-53.

[5] Zhou Zhongzhi, Marketing strategy research of RT Mart Xiangfang store in new retail environment[D]. Harbin Institute of technology, 2019.
[6] Bai Jin. Huludao RT Mart supermarket marketing strategy research[D]. Liaoning University of Engineering and Technology, 2018.

[7] Gao Dong. Analysis on the marketing strategy of China's large supermarket chains: a case study of RT Mart[J]. Science and Technology Information, 2017,15 (24): 48-54.

[8] Xia Wanting. Fuxin RT Mart comprehensive supermarket marketing strategy research[D]. Liaoning, Liaoning University of Engineering and Technology, 2017.

[9] Ge Ping. Marketing strategy research of RT Mart chain supermarket in Weifang[D]. Harbin University of Technology, 2016.

[10] Wei Yuanyuan, Dong Minhua. Marketing strategy analysis of Wenzhou RT Mart supermarket[J]. Modern Economic Information, 2018, (30): 35-39.

[11] Qu Yanan. Application analysis of marketing channel management in diversified markets[J]. Fortune Today, 2021, (10): 46-48.

[12] Liu Juan, Xu Gang, Chen Ying, Zhu Xue. Silver marketing of hotel industry in post epidemic era[J]. Management and Technology of Small and Medium Sized Enterprises, 2021, (05): 52-55.

[13] Gao Xianmin. Research on the Countermeasures for the expansion of traditional retail industry to E-commerce -Taking RT mart's "Feiniu net" as an example[D]. Shandong Normal University, 2017. 